\title{
Patients seeking information about colonoscopy - lessons learned from Google
}

\author{
Dariusz Łaski ${ }^{1}$, Adrian Perdyan ${ }^{2}$, Piotr Spychalski ${ }^{1}$, Andrzej J. Łachiński ${ }^{1}$, Zbigniew Śledziński ${ }^{1}$, \\ Anna Tybińkowska ${ }^{3}$, Jarek Kobiela ${ }^{1}$ \\ ${ }^{1}$ Department of General, Endocrine, and Transplant Surgery, Medical University Gdansk, Gdansk, Poland \\ 'Students' Scientific Circle at the Department of General, Endocrine, and Transplant Surgery, Medical University of Gdansk, \\ Gdansk, Poland \\ ${ }^{3}$ Department of Marketing, Faculty of Management and Economics, Gdansk University of Technology, Gdansk, Poland
}

Gastroenterology Rev 2020; 15 (2): 144-150

DOI: https://doi.org/10.5114/pg.2020.95557

Key words: colonoscopy, Google trends, search engine, Internet.

Address for correspondence: Adrian Perdyan, Students' Scientific Circle at Department of General, Endocrine, and Transplant Surgery, Medical University of Gdansk, 3A Sklodowskiej St, 80-210 Gdansk, Poland, phone: +48 503131 881, e-mail: perdyan.adrian@gumed.edu.pl

\begin{abstract}
Introduction: Every year in the USA over 14 million colonoscopies are performed. It requires high-quality examinations as well as a relevant information strategy. Colonoscopy compliance is not satisfactory, which to some extent might be related to patients' attitudes towards colonoscopy, which are based on information and emotions.

Aim: In the current study we addressed the questions of what kind of information people seek and get when they search the Internet for "colonoscopy".

Material and methods: Using the Google Trends web facility we analysed search results of "colonoscopy", related searches, and annual and weekly search trends. Fields of interest analysis was performed based on the related searches.

Results: Patients are generally offered quality data on the first result page of a Google search biased only by Wikipedia scoring first on the result list. The number of "colonoscopy" searches is stable over the week with a significant decrease on weekends, and stable over the year with significant decrease around Thanksgiving day and in the Christmas/New Year's Eve Period. The most common field of search is colonoscopy preparation, thus underlining the importance of this part of colonoscopy.

Conclusions: Internet search provides abundant information on colonoscopy. In general, this information is accessible, preferred by patients, and of good quality. This should be kept in mind by healthcare providers while educating patients about colonoscopy.
\end{abstract}

\section{Introduction}

Every year in the USA over 14 million colonoscopies are performed [1]. These numbers create organisational and financial challenges for the healthcare system. It requires healthcare providers and policy makers not only to provide high-quality examinations but also a relevant information strategy. It was found that $50-80 \%$ of patients use the Internet to find medical and health information [2, 3]. Fifty-nine percent of them do not discuss the obtained information with their doctors, and $11 \%$ use medical advice from Internet instead of contacting healthcare professionals [2]. Patients' navigation and compliance with colonoscopy screening recommendations is not satisfactory, which to some extent might be related to patients' attitudes towards colonoscopy, attitudes that are based on information as well as emotions. Nevertheless, it has been proven that this can be influenced by properly tailored educational programs [4]. Education efforts towards patients made by healthcare staff in general have proven to be effective [5].

\section{Aim}

In this study we aim to assess behaviour of Internet users searching for information on colonoscopy and the quality of the found information. Moreover, we discuss our findings in the context of patient education.

\section{Material and methods}

The Google search engine is the most popular search engine in US and worldwide [6]. For this reason, 
analysis was based on the statistics of this engine. Google Trends is a public web facility of Google LLC, which presents how often a particular search-term is entered relative to the total search-volume in a specified time, across various regions of the world, and in various languages [7]. An exact number of searches is not publicly available and cannot be obtained for scientific purposes because it is protected by the company.

Using the Google Search web facility, the first 30 search results of "colonoscopy" were obtained. Before performing a Google search, the browser history (Chrome - Google, LLC) was cleared and all cookie files were removed to prevent personalised search results. Related searches were analysed. Search results were categorised according to the source of information into two groups: professional resources - web sites of medical institutions, societies, academic, or hospital facilities; non-professional resources - open forums web sites, blogs, non-medical journals and websites, etc. Categorisation was performed independently by three medical doctors, and the final group assignment was decided based on the majority of votes. The first 50 related searches were obtained from Google Trends and categorised into groups according to the field of interest. Categorisation was performed independently by three medical doctors, and the final group assignment was decided based on the majority of votes. After several rounds of voting the following seven main topics were created and are listed further in the Results section.

\section{Results}

The first 30 search results for the keyword "colonoscopy" are listed in Tables I (worldwide) and II (in Poland). Each of the web sites was visited to categorise the source of medical information as described in the methods section. The annual change in trends of searching for the keyword "colonoscopy" worldwide was looked up for the last 5 years, revealing a stable number of searches over the year with two significant decreases - on Thanksgiving day and during the Christmas/New Year's Eve Period (Figure 1 A). Trends analysis was also provided for Poland independently using the same keyword in Polish, "kolonoskopia", which showed a very similar trend (Figure 1 B), with decreases at the beginning of May and the holidays in July, and the Christmas/New Year's Eve Period. Weekly change of trend in searches for the keyword "colonoscopy" was analysed for the last 5 weeks, revealing a decrease of more than $20 \%$ during weekends (Figure 2). The 50 most common searches related with the keyword "colonoscopy" were analysed. The main topics of related searches worldwide are listed below, from the most to the least popular:
1. Preparation for colonoscopy.

2. What is colonoscopy - indications, procedure?

3. What after colonoscopy?

4. Detailed information about colonoscopy (i.e. "where to do it?", "how much does it cost?").

5. Topics associated with fear, pain, side effects.

Table I. The 30 most popular worldwide search results for "colonoscopy", with the type of source

\begin{tabular}{|c|c|}
\hline Links in order of search results & Source \\
\hline en.wikzpedia.org & Non-professional \\
\hline http://www.webmd.com & Professional \\
\hline http://www.medicinenet.com & Professional \\
\hline http://www.mayoclinic.org & Professional \\
\hline http://www.cancer.org & Professional \\
\hline http://www.patient.co.uk & Professional \\
\hline http://www.gastro.org & Professional \\
\hline http://www.niddk.nih.gov & Professional \\
\hline http://www.nlm.nih.gov & Professional \\
\hline http://www.emedicinehealth.com & Professional \\
\hline http://www.asge.org & Professional \\
\hline http://www.bupa.co.uk & Professional \\
\hline http://www.betterhealth.vic.gov.au & Professional \\
\hline http://www.nhs.uk & Professional \\
\hline http://patients.gi.org & Professional \\
\hline http://www.cancerscreening.nhs.uk & Professional \\
\hline https://www.youtube.com & Non-professional \\
\hline http://www.ccalliance.org & Professional \\
\hline http://www.health.harvard.edu & Professional \\
\hline http://www.macmillan.org.uk & Professional \\
\hline http://wiki.cancer.org.au & Professional \\
\hline http://www.sages.org & Professional \\
\hline http://www.hufjingtonpost.com & Non-professional \\
\hline http://www.forbes.com & Non-professional \\
\hline http://www.surgerysquad.com & Non-professional \\
\hline http://www.dailymail.co.uk & Non-professional \\
\hline http://www.choosingwisely.org & Professional \\
\hline https://www.facs.org & Professional \\
\hline https://www.beatingbowelcancer.org & Professional \\
\hline http://www.med.umich.edu & Professional \\
\hline
\end{tabular}


6. Virtual colonoscopy.

7. Not related to colonoscopy.

These can be taken as an equivalent for the Polish population unless the most popular topic in Poland was "how much does it cost?"

Analysis of historical trends for last 10 years showed that the main point of interest is preparation for colonoscopy. Searches did not change by more than $5 \%$ in a 4-year period. The only exception is the keyword "virtual colonoscopy", which was a top search at the beginning of the analysis period and was almost totally marginalised at the end of analysis period, with a fivefold decrease in the global number of searches over the last 10 years.

\section{Discussion}

The Internet has become an essential part of our daily life, affecting the way we communicate and work. It has also changed the way patients obtain health-related information. Ninety-four percent of Internet users use search engines like Google, Bing, Yahoo! etc. to look for medical information on the Internet [3]. Google is the world's most popular search engine, with a market share of $72.68 \%$ as of May 2018 [8]. East Asian countries and Russia constitute the few places where Google is not the most popular search engine [9]. Most of the users go only through the first page of search results, and if they are not satisfied with what they find, they change or extend the keyword, which creates related searches. It was shown that most users do not check more than the first 30 search results [2]. In our study $80 \%$ of the top 30 results worldwide returned are from professional sources. However, number one is Wikipedia, a publicly editable source of variable reliability. It is the only non-professional source in the top-ten results. Nevertheless, it should be mentioned that Wikipedia, despite being a crowd-based project, remains an encyclopaedia. According to five pillars of Wikipedia, "All articles must strive for verifiable accuracy, citing reliable, authoritative sources (...)" and therefore it is a source of knowledge that often offers quality content. Despite that, we advise against using it as a reference source of information because it can be edited by any willing party, so any information acquired from it should be verified [10]. Moreover, it must be remembered that $62 \%$ of patients rate medical information retrieved from the Internet as excellent or very good [2]. Patients consider the information as reliable if it is sponsored by a medical society, medical professionals, university, or hospital. They consider it less reliable (13-16\%) if it sponsored by a pharmaceutical company or is advertised in the media (TV, radio, etc.) [2]. In the evaluation of the usefulness of various sources of med-
Table II. The 30 most popular search results in Poland for "colonoscopy", with the type of source

\begin{tabular}{|c|c|}
\hline Links in order of search results & Source \\
\hline pl.wikipedia.org & Non-professional \\
\hline http://www.medonet.pl & Professional \\
\hline http://www.zdrowie.pap.pl & Professional \\
\hline http://www.termedia.pl & Professional \\
\hline http://www.apteline.pl & Professional \\
\hline http://www.coi.pl & Professional \\
\hline http://www.medicover.pl & Professional \\
\hline http://www.sante-cm.pl & Professional \\
\hline http://www.io.gliwice.pl & Professional \\
\hline http://www.cm.enel.pl & Professional \\
\hline http://www.wmed.com.pl & Professional \\
\hline http://www.izito.pl & Non-professional \\
\hline http://www.zapmeta.com.pl & Non-professional \\
\hline http://www.youtube.com & Non-professional \\
\hline http://www.sages.org & Professional \\
\hline https://www.szpitalrydygier.pl & Professional \\
\hline http://www.nfz-szczecin.pl & Professional \\
\hline htt://www.zozmedical.pl & Professional \\
\hline http://www.onkologia.org.pl & Professional \\
\hline http:/lwww.hvaned.pl & Professional \\
\hline http:/lwww.mp.pl & Professional \\
\hline http://www.ecz-otwock.pl & Professional \\
\hline http://www.nowyszpital.pl & Professional \\
\hline http://search.visymo.com & Non-professional \\
\hline http://www.betamed.pl & Professional \\
\hline http://www.zdrowie.radiozet.pl & Non-professional \\
\hline https://www.damian.pl & Professional \\
\hline https://www.medme.pl & Non-professional \\
\hline http://www.medexpress.pl & Professional \\
\hline http://www.kobieta.onet.pl & Non-professiona \\
\hline
\end{tabular}

ical information, patients score the Internet very highly (5.05 out of 7) compared to information given by their physician (6.09 out of 7) [2]. The results of our study suggest that patients are generally offered quality data on the first page of a Google search. On average 61\% of people visit from two to five health-related websites 


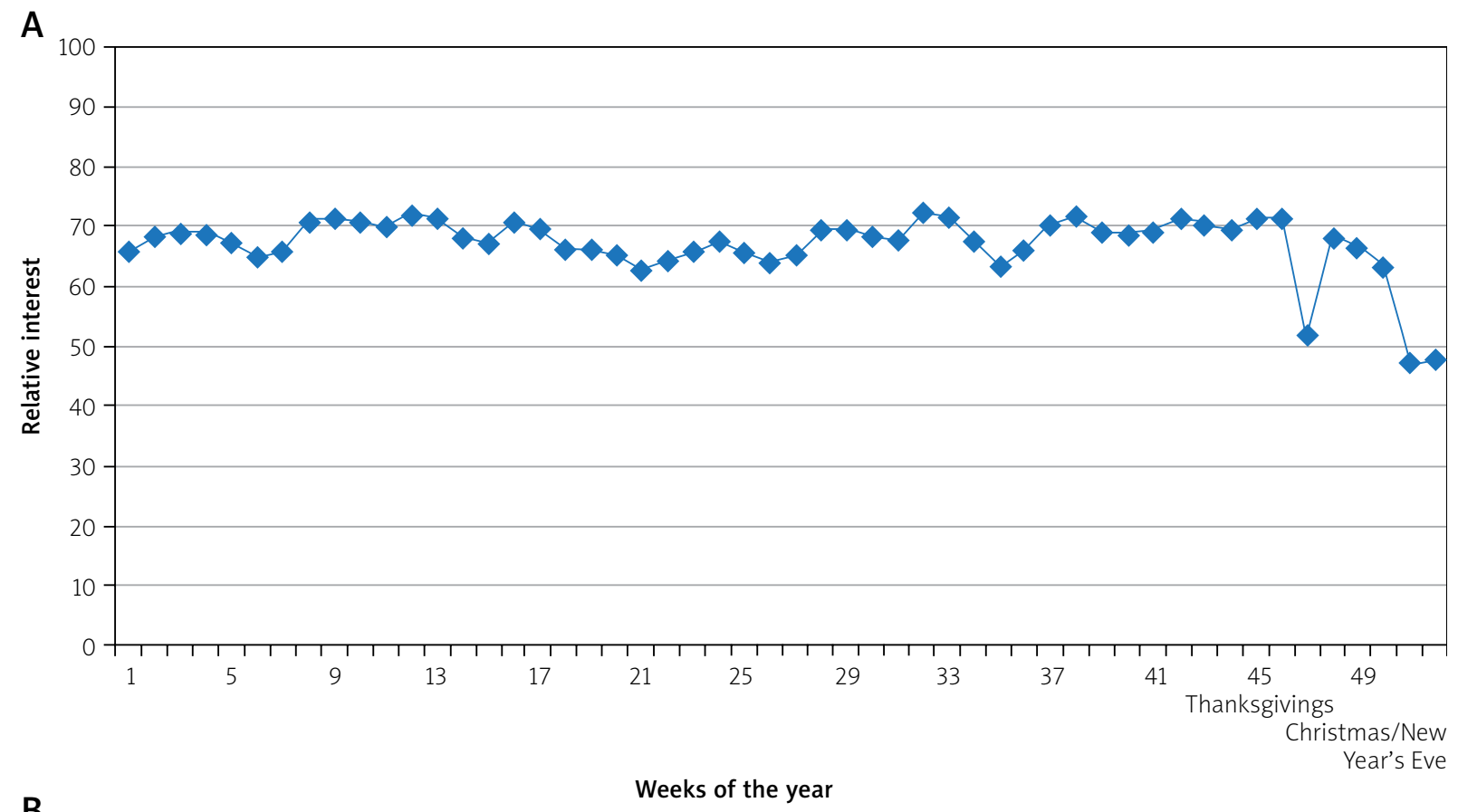

B

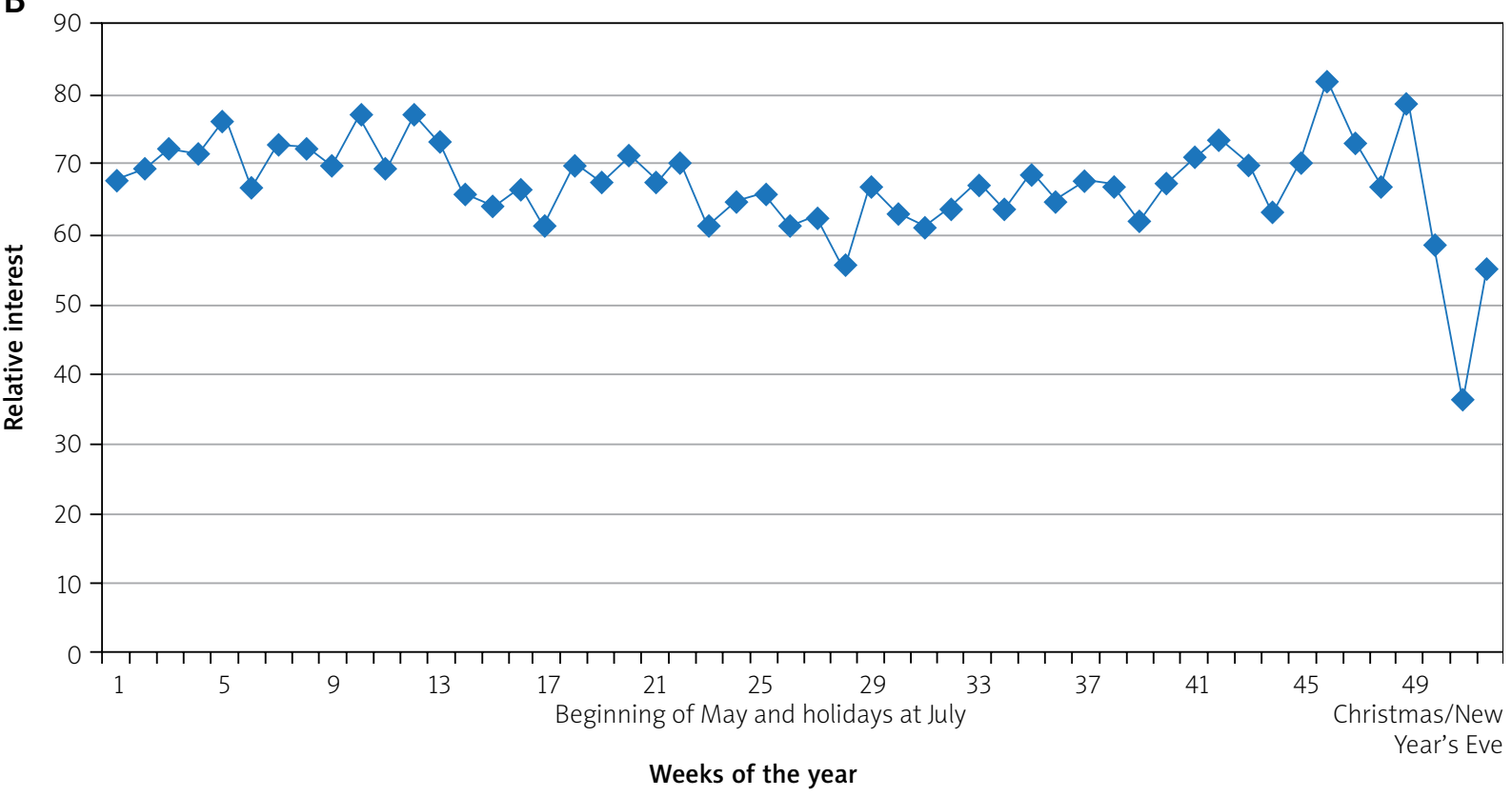

Figure 1. A - Yearly change of the number of search results worldwide for the keyword "colonoscopy". B - Yearly change of the number of search results for the keyword "colonoscopy" in Poland

and $25 \%$ check from 6 to 10 web sites [3]. Each page of search engine results contains 10 listings. The listings that are on the first page are the most important ones because they get $91 \%$ of the click through rates (CTR) from a particular search [11]. The CTRs for the first page are as follows: $30 \%$ of users check five web sites from the top, $20 \%-10$ web sites from the top, and $38 \%$ - more than 10 web sites from the top [3]. These facts need to be taken in consideration when planning Internet positioning of public campaigns and educational strategies.

In general the most frequently searched health topics are those associated with civilisation diseases - cardiovascular diseases, cancer and related prophylaxis, diabetes, exercise, and weight loss [2]. The number of "colonoscopy" searches is stable over the year with evident decreases around Thanksgiving day and during the Christmas/New Year's Eve Period. This seems to repre- 


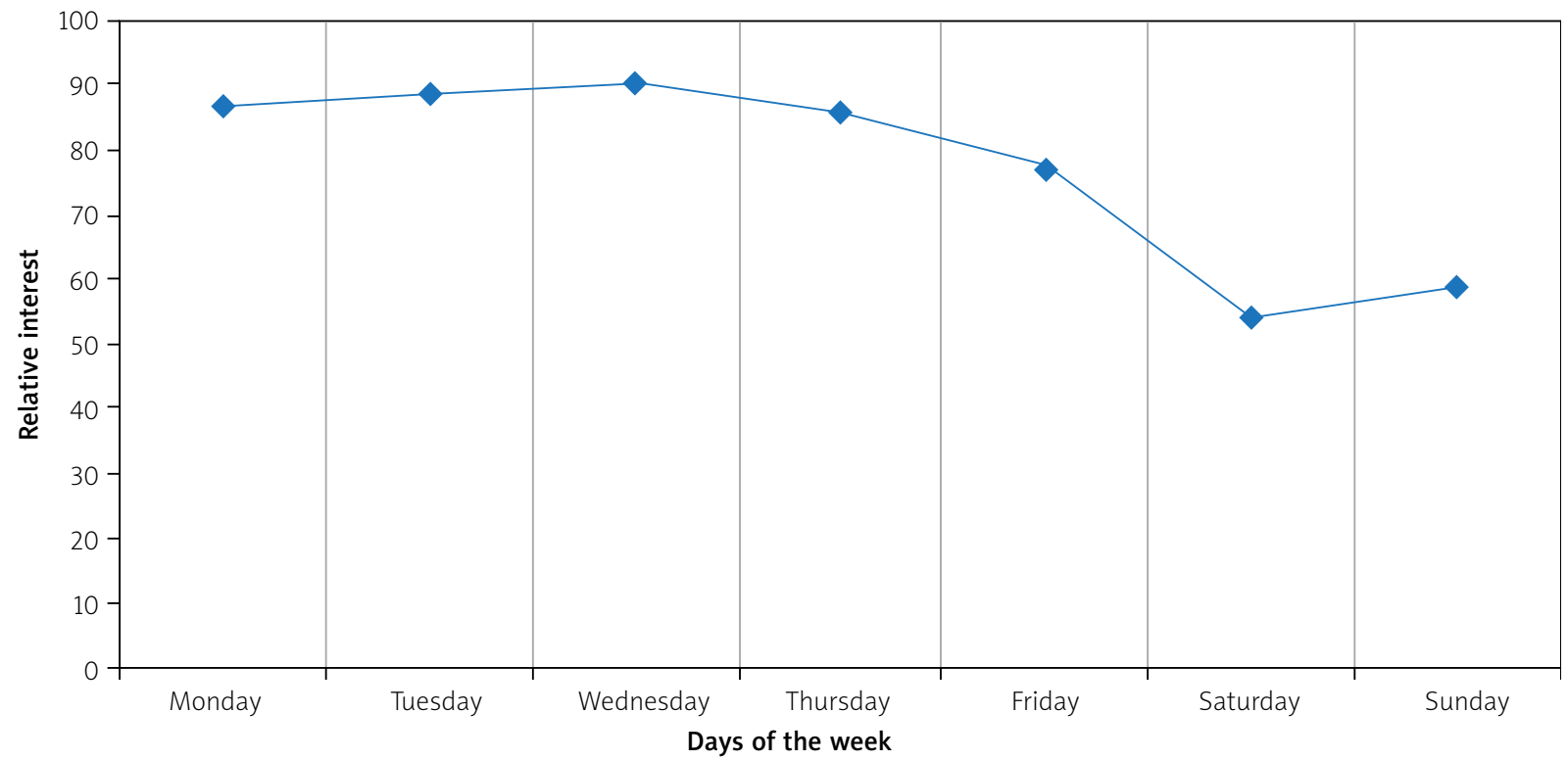

Figure 2. Weekly change in number of searches for the keyword "colonoscopy"

sent the decreased number of scheduled examinations in these periods. We presume a significant proportion of people who search for "colonoscopy" consider or were offered this examination either in screening or indication-based setting. The distribution of "colonoscopy" searches in relation to the preparation and examination day is not known; however, we suppose, based on the related searches topics, that almost all of the searches are done before rather than after the scheduled examination. In a study by Diaz et al. $60 \%$ of patients responded that information obtained from the Internet is the same quality or even better than the information given by their doctor [2]. The number of "colonoscopy" searches in our study decreases significantly during weekends, and according to Alexa Reference the majority of searches are done at work [12]. It is difficult to elucidate whether this simply illustrates the working days of endoscopy offices or defines colonoscopy as an issue to be explored at work rather than a family issue to be raised during weekends.

Related searches are an important source of information on what people are actually looking for. Although the most common related search was "colonoscopy prep", the number of returned results was slightly over 400,000 compared to nearly 10 million returned results for the sole keyword "colonoscopy". The number of results for more general enquiries such as "endoscopy" or "colon cancer" was even higher, reaching over 18 and 16 million returned results, respectively. This represent the general mechanism of searching the Internet by typing more precise keywords to obtain more accurate results. Out of the seven related search categories the most searched was "preparation for colonoscopy", which scored one, six, and seven related searches. Analysis of search trends for the last 10 years revealed this search to be constantly the top related search over the years. This represents interest in this part of the procedure, which is done mostly at home prior to the actual procedure without direct supervision of a healthcare professional. Considering that this is the part of the procedure being reported in several studies to be worse than actual scoping of the bowel, efforts should be made to ensure reliable and explanatory sources for the patients [13, 14]. Results of Internet searches can potentially discourage people from attending colonoscopy. One of the successfully used remedies was a specially designed smartphone application, which was used to improve bowel preparation quality and patient satisfaction [15]. The second most common topic within the related searches is general information - "what is colonoscopy?", "how and why it is done?" The third most common related search is "what happens after colonoscopy?" Surprisingly, issues associated with pain, side effects, and other worries scored fifth amongst the most common, constituting approximately $10 \%$ of related searches requesting data on preparation. This finding is contrary to the concept that people fear colonoscopy and focus on the disadvantages of colonoscopy, thus leading to screening nonattendance [16]. Providing quality data sources and correcting misunderstandings arising from nonprofessional sources seems to be a crucial role of healthcare providers. This might be of great importance when the patient is deciding whether to attend colonoscopy. Most 
of the top website results obtained when searching for "colonoscopy" mention colonoscopy screening as a way of diagnosing colorectal cancer, and this might be an important factor for the patient to attend screening, or adversely not to attend a screening examination in cancerphobic individuals.

The relationship and communication between patients and medical staff plays a crucial role in patient satisfaction and compliance. It has been reported that improving the patient-provider relationship may improve colorectal cancer screening [4]. Moreover, it has been demonstrated that improving education of the staff improves patient-related factors of successful colonoscopy such as bowel preparation [17]. Further what improves compliance it is patients navigation a community-based service delivery intervention designed to promote proper assessment of diagnosis and treatment in cancer and other chronic diseases. Its purpose is to eliminate barriers of care. Common barriers to overcome are as follows: finances, insurance costs, disinformation, miscommunication, medical system issues, fear, distrust, and emotions. All of the abovementioned can potentially improve quality of care on many levels, ranging from higher patient satisfaction to improving adenoma detection rates. Therefore, it should be highlighted that the Internet is a source of knowledge that is of adequate quality. Consequently, patients should not be discouraged from using it, especially taking into consideration that it is often the medium of their choice [18].

Strengths of our study include the novel methodology facilitating Google Trends. This tool provides a unique perspective into the behaviour of the average Internet user. Furthermore, our study provides an important insight into the quality of information available on the Internet, which is a subject of common criticism. Facilitating Google Trends to analyse the behaviour of Internet users bears some limitations as well, the first of which is the fact that the absolute number of searches is not available, even on request for scientific purposes, from Google LLC. This information embargo may be seen as controversial because it could be potentially beneficial for public health strategies. A further existing limitation is the lack of possibility to determine whether the searches performed by patients, which contribute to the Google Trends scores, where done before or after supposed colonoscopy. Google Trends allows only a general analysis of behaviour without an in-depth view of the users' actions. It would be also interesting to track important press releases with regard to the used keywords, but this is unfortunately impossible to do using Google Trends due to a lack of such a search option. On the other hand, it is a free, accessible, and intuitive tool that may be used by untrained personnel. A good example of a positive contribution of the Google search engine to public health is Google Flu Trends functionality, which, based on certain search terms, estimates flu activity in world regions. Similar analysis for colorectal cancer symptoms' searches could help to identify regions and populations of high screening requirements. This would be a very beneficial use of widely criticised data collection and monitoring by search engines. Another limitation present in our study is the methodology of assessing whether a website has "professional" or "non-professional" information. Firstly, as with all subjective assessments, in can be argued that some of the websites were categorised incorrectly. The previously mentioned example of Wikipedia could be claimed for both sides: as professional, because it is bibliography-based, and non-professional, because it can be freely edited. Secondly, our assessment did not take into consideration the funding of the analysed websites (e.g. non-profit, government, pharmaceutical companies); however, we recognise that this could have potentially biased the results.

\section{Conclusions}

Analysis of search engine search trends may be a useful tool. Knowledge on the behaviour of patients seeking information may be used to improve the availability of quality data, tailor results, and contribute to healthcare policies and educational programs. Moreover, Internet searches provide abundant information on colonoscopy. In general, this information is accessible, preferred by patients, and of good quality. This should be kept in mind both by policymakers and healthcare providers while educating patients about colonoscopy.

\section{Acknowledgments}

We would like to acknowledge Rebecca Harsten MD who contributed to an early stage of this study.

\section{Conflict of interest}

The authors declare no conflict of interest.

\section{References}

1. Kruse GR, Khan SM, Zaslavsky AM, et al. Overuse of colonoscopy for colorectal cancer screening and surveillance. JGIM 2015; 30: 277-83.

2. Diaz JA, Griffith RA, Ng J, et al. Patients' use of the Internet for medical information. JGIM 2002; 17: 180-5.

3. Pletneva N, Vargas A, Kalogianni K, et al. Online health information search: what struggles and empowers the users? Results of an online survey. Stud Health Technol Inform 2012; 180: 843-7. 
4. Kalayjian E, Bringman D, Naughton A, et al. Improving adherence to screening colonoscopy preparation and appointments. Gastroenterol Nurs 2015; 38: 408-16.

5. Cinar S, Ozdogan OC, Alahdab Y. Impact of education provided by nurses on quality of life, anxiety, and depression in patients receiving hepatitis C virus therapy. Gastroenterol Nurs 2015; 38: 343-7.

6. Jain V, Raut DK. Medical literature search dot com. Indian J Dermatol Venereol Leprol 2011; 77: 135-40.

7. The homepage explained - Trends Help.

8. Search engine market share.

9. Wang L, Wang J, Wang M, et al. Using Internet search engines to obtain medical information: a comparative study. J Med Internet Res 2012; 14: e74.

10. Wikipedia: Five pillars - Wikipedia.

11. Case Study: 91\% of Browsers Don't Click on Second Page|Seo Take Over.

12. Keyword Research, Competitive Analysis, \&amp; Website Ranking|Alexa.

13. Harewood GC, Sharma VK, Garmo P. Impact of colonoscopy preparation quality on detection of suspected colonic neoplasia. Gastrointest Endosc 2003; 58: 76-9.

14. Nicholson FB, Korman MG. Acceptance of flexible sigmoidoscopy and colonoscopy for screening and surveillance in colorectal cancer prevention. J Med Screen 2005; 12: 89-95.

15. Lorenzo-Zúñiga V, Moreno de Vega V, Marín M, et al. Improving the quality of colonoscopy bowel preparation using a smart phone application: a randomized trial. Dig Endosc 2015; 27: 590-5.

16. Denberg TD, Melhado TV, Coombes JM, et al. Predictors of nonadherence to screening colonoscopy. JGIM 2005; 20: 989-95.

17. Lee YJ, Kim ES, Park KS, et al. Education for ward nurses influences the quality of inpatient $s$ bowel preparation for colonoscopy. Medicine 2015; 94: e1423.

18. Freeman HP, Rodriguez RL. The History and principles of patient navigation. Cancer 2011; 117: 3539-42.

Received: 17.09 .2018

Accepted: 17.06.2019 